\title{
Erratum to: Enhancing the efficiency of luminescent solar concentrators (LSCs)
}

\author{
M. Khalaji Assadi ${ }^{1}$ H. Hanaei ${ }^{1}$ Norani Muti Mohamed ${ }^{2} \cdot$ R. Saidur ${ }^{3}$. \\ Shokoufeh Bakhoda ${ }^{1} \cdot$ Robabeh Bashiri $^{4} \cdot$ M. Moayedfar ${ }^{1}$
}

Published online: 10 March 2017

(C) Springer-Verlag Berlin Heidelberg 2017

\section{Erratum to: Appl. Phys. A (2016) 122:821 \\ DOI 10.1007/s00339-016-0359-2}

The original version of this article unfortunately contained a mistake.

The acknowledgement paragraph was missing. The correct acknowledgement is given here.

\begin{abstract}
Acknowledgements The authors would like to express gratitude to the Universiti Teknologi PETRONAS for the financial support provided under the Fundamental Research Grant Scheme (FRGS) Grant, cost center: 0153AB-K88.
\end{abstract}

The online version of the original article can be found under doi:10.1007/s00339-016-0359-2.

H. Hanaei

hengameh_hanaei@yahoo.com

1 Mechanical Engineering Department, University Teknologi PETRONAS, Bandar Seri Iskandar, Perak, Malaysia

2 Fundamental and Applied Sciences Department, Universiti Teknologi PETRONAS, Bandar Seri Iskandar, Perak, Malaysia

3 Centre of Research Excellence in Renewable Energy (CoRERE), King Fahd University of Petroleum and Minerals (KFUPM), Dhahran, Kingdom of Saudi Arabia

4 Chemical Engineering Department, Universiti Teknologi PETRONAS, Bandar Seri Iskandar, Perak, Malaysia 